\title{
Elevated plasma endothelin as an additional cardiovascular risk factor in patients with Cushing's syndrome
}

\author{
G Kirilov, A Tomova, L Dakovska, Ph Kumanov, A Shinkov and A S Alexandrov ${ }^{1}$ \\ Clinical Center of Endocrinology, Medical University, Sofia, Bulgaria and ${ }^{1}$ Institute of Biophysics, Bulgarian Academy of Sciences, Sofia, Bulgaria \\ (Correspondence should be addressed to G Kirilov, Clinical Center of Endocrinology, 6 Blvd Damian Gruev, 1303-Sofia, Bulgaria; \\ Email: kirilov@uheg.medicalnet-bg.org)
}

\begin{abstract}
Background: Recently the pathophysiological role of endothelin (ET) has been presumed in a number of adrenal disorders such as primary hyperaldosteronism, pheochromocytoma and adrenocortical insufficiency.

Aim: The aim of the present study was to evaluate circulating ET-1 levels in patients with endogenous Cushing's syndrome.

Methods and results: Plasma ET-1 levels were determined by highly sensitive RIA. Thirteen untreated subjects with Cushing's syndrome were studied: eight women and five men of mean age 44.2 29.5 years (S.D.). In ten of them, Cushing's disease had been diagnosed and three had adrenal adenomas. ET-1 was 3-fold higher in the patient group than in age-matched healthy controls $(n=13)$ : $1.59 \pm 0.78$ vs $0.46 \pm 0.20 \mathrm{pmol} / \mathrm{l}$ respectively, $P<0.001$. In adrenal adenoma patients, ET- 1 was not significantly higher than in the Cushing's disease subjects $(1.84 \pm 0.67$ vs $1.51 \pm 0.83 \mathrm{pmol} / \mathrm{l}$ respectively, $P>0.05)$. In three patients who died of severe cardiovascular complications, plasma ET-1 was significantly higher than in the remaining patients $(2.34 \pm 0.35 \mathrm{pmol} / \mathrm{l}, P<0.05)$. A positive correlation was found between the total cholesterol $(6.94 \pm 1.75 \mathrm{mmol} / \mathrm{l})$ and ET-1 levels in the patients with Cushing's syndrome: $r=+0.73, P<0.02$. No correlation was observed, however, between the levels of ET-1 and blood pressure $(183 \pm 37 / 106 \pm 18 \mathrm{mmHg})$, plasma cortisol levels $(455.2 \pm 74.5 \mathrm{nmol} / \mathrm{l})$ or urinary cortisol excretion $(1463 \pm 726 \mathrm{nmol} / 24 \mathrm{~h})$. The successful treatment and correction of hypercortisolism in seven patients led to insignificant reduction in plasma ET from $1.34 \pm 0.69$ to $0.73 \pm 0.53 \mathrm{pmol} / \mathrm{l}, P>0.05$.

Conclusion: Our results clearly demonstrate that the ET system is activated in Cushing's syndrome. Elevated plasma ET-1 levels probably play a role in the pathogenesis of accelerated and early atherosclerosis development in this disorder.
\end{abstract}

European Journal of Endocrinology 149 549-553

\section{Introduction}

Recently, many experimental and clinical studies have been published confirming the role of endothelin (ET) as a stimulator and modulator of hypothalamic-pituitary-adrenal function (1-4). The ETs are classified in the group of the neuroendocrine peptides, which is illustrated by the fact that ET-1 stimulates the hypothalamic release of corticotropin-releasing hormone $(\mathrm{CRH})$ and pituitary secretion of adrenocorticotropic hormone (ACTH) via specific ET-A and ET-B receptors (5). On the other hand, it was found that ET is a local adrenomedullary and adrenocortical paracrine regulator. The genes of both ET and its converting enzyme and receptors are expressed by human adrenocortical cells (6). Thus, ET stimulates cortisol and aldosterone secretion directly and by enhancing ACTH action. Together with nitric oxide (NO) it regulates the adrenal vascular tone and stimulates adrenal growth $(7,8)$. It was demonstrated that glucocorticosteroids induce ET release by vascular smooth muscle cells, suppress the activity of the NO system and thus cause vasoconstriction, endothelial dysfunction and atherosclerosis (9).

From this point of view, in conditions associated with hypercortisolism, plasma ET assessment is by all means justified, insofar as it may reveal eventual pathophysiological implications of this vasoactive peptide. What is more, in a number of adrenal diseases, such as primary hyperaldosteronism, pheochromocytoma and adrenal insufficiency, plasma ET levels undergo significant changes (10-12). Proceeding from already discussed experimental and clinical data concerning the role of ET in adrenal physiology and pathology, we undertook to evaluate the levels of plasma immunoreactive ET in patients with Cushing's syndrome. 


\section{Material and methods}

The study was carried out under clinical conditions, and covered 13 patients with Cushing's syndrome: eight women and five men of mean age 44.2 \pm 9.5 years (S.D.). Ten of them had Cushing's disease (ACTH-dependent Cushing's syndrome) and three had adrenal adenomas. The major clinical and laboratory data on the patients are presented in Table 1. Three of the patients died of severe cardiovascular complications.

The diagnosis was based on the clinical signs and symptoms (central redistribution of fat, hypertension, osteoporosis, muscle weakness, hirsutism), hormonal data (elevated plasma and urinary free cortisol levels, increased ACTH concentrations in patients with Cushing's disease and decreased in those with adrenal adenomas). Computed tomography scans were used to define adrenal and pituitary lesions. The study was completed during the active stage of the disorder in the condition of manifest hypercortisolism and no medication for at least 1 week. Renal function was intact in all patients. Plasma ET was measured in only seven subjects treated for Cushing's syndrome in whom clinical and laboratory remission was achieved: one with adrenal adenoma treated by adrenalectomy and six with Cushing's disease treated by transsphenoidal adenomectomy. The remaining three patients, in whom no satisfactory remission was reached and hypercortisolism persisted, were not included in the post-treatment follow-up.

Thirteen age-matched healthy subjects aged $41 \pm 6.5$ years (five males and eight females) served as controls. All the patients and controls gave informed consent to the study, which was approved by the local Ethics Committee of the Clinical Center of Endocrinology, Sofia.

Plasma levels of ET were measured in blood samples taken in the morning between 0830 and $0900 \mathrm{~h}$ after an overnight fast. Before the blood samples were taken, the patients rested in the supine position for at least $30 \mathrm{~min}$. After centrifugation, plasma samples were frozen at $-20^{\circ} \mathrm{C}$. Plasma ET-1 levels were determined by sensitive RIA (Biomedica, Vienna, Austria) after an extraction procedure on Sep-Pak C18 cartridges (Waters, Milford, MA, USA). Intra-assay and interassay coefficients of variation were 3 and $11.9 \%$ respectively. The sensitivity of the assay is $0.1 \mathrm{fmol} /-$ tube; cross-reactivity with ET-2 is $142 \%$, and that with ET-3 98\%. All plasma samples were assayed in the same run and at least in duplicate.

The plasma cortisol levels and the $24 \mathrm{~h}$ free urinary cortisol excretion were measured by spectrofluorimetric analysis, and ACTH by two-site IRMA. Normal values were plasma cortisol $(0800 \mathrm{~h}) \quad 166-441 \mathrm{nmol} / \mathrm{l}$; $24 \mathrm{~h}$ free urinary cortisol excretion in females 221-552 nmol $/ 24 \mathrm{~h}$, in males $248-828 \mathrm{nmol} / 24 \mathrm{~h}$; ACTH (0800 h) 2.2-15.8 pmol/l.

Statistical evaluation of the data was carried out on a computer using nonparametric analysis with the Mann-Whitney test and Student's t-test. Linear correlation coefficients were calculated to describe the association between continuous variables. The results are expressed as means \pm S.D. $P<0.05$ was considered statistically significant.

\section{Results}

Plasma ET-1 levels were significantly elevated in Cushing's syndrome, as compared with healthy controls $(1.59 \pm 0.78$ vs $0.46 \pm 0.20 \mathrm{pmol} / \mathrm{l}$ respectively, $P<0.001$, Fig. 1). There was a 3 -fold increase. The individual analysis of the data demonstrated highest ET levels in the patients who died subsequently $(n=3)$ of severe cardiovascular complications $(2.34 \pm 0.35 \mathrm{pmol} / \mathrm{l}, P<0.05)$. Patients with adrenal adenomas $(n=3)$ had higher ET-1 levels than the ones with Cushing's disease $(n=10)$, but the difference was not significant $(1.84 \pm 0.67$ vs $1.51 \pm 0.83 \mathrm{pmol} / \mathrm{l}$, $P>0.05)$. Both systolic and diastolic blood pressure were significantly higher in hypercortisolemic patients

Table 1 Clinical and laboratory characteristics of patients with Cushing's syndrome and in normal controls. Values are means \pm S.D.

\begin{tabular}{|c|c|c|c|}
\hline & $\begin{array}{l}\text { Patients with Cushing's } \\
\text { syndrome }(n=13)\end{array}$ & $\begin{array}{l}\text { Normal controls } \\
\qquad(n=13)\end{array}$ & $\boldsymbol{P}$ \\
\hline Gender (male/female) & $5 / 8$ & $5 / 8$ & - \\
\hline Cushing's disease/adrenal adenomas & $10 / 3$ & - & - \\
\hline Age (years) & $44.2 \pm 9.5$ & $41 \pm 6.5$ & 0.326 \\
\hline Duration of disease (years) & $6.8 \pm 8.4$ & - & - \\
\hline Urinary free cortisol (nmol/24 h) & $1463 \pm 726$ & $772.7 \pm 181$ & 0.003 \\
\hline Plasma cortisol: $0800 \mathrm{~h}$ (nmol/l) & $455.2 \pm 74.5$ & $333.8 \pm 49.6$ & $<0.001$ \\
\hline Plasma cortisol: $2200 \mathrm{~h}$ (nmol/l) & $416.6 \pm 118.6$ & $256.6 \pm 44.1$ & $<0.001$ \\
\hline Systolic blood pressure (mmHg) & $183 \pm 37$ & $107 \pm 2.6$ & $<0.001$ \\
\hline Diastolic blood pressure (mmHg) & $106 \pm 18$ & $75 \pm 2.6$ & $<0.001$ \\
\hline Serum potassium $(\mathrm{mmol} / \mathrm{l})$ & $4.3 \pm 0.65$ & $4.5 \pm 0.11$ & 0.285 \\
\hline Total cholesterol (mmol/l) & $6.94 \pm 1.75$ & $4.7 \pm 1.1$ & $<0.001$ \\
\hline Triglycerides $(\mathrm{mmol} / \mathrm{l})$ & $3.07 \pm 3.57$ & $1.3 \pm 0.6$ & 0.091 \\
\hline Plasma ET (pmol/l) & $1.59 \pm 0.78$ & $0.46 \pm 0.2$ & $<0.001$ \\
\hline
\end{tabular}




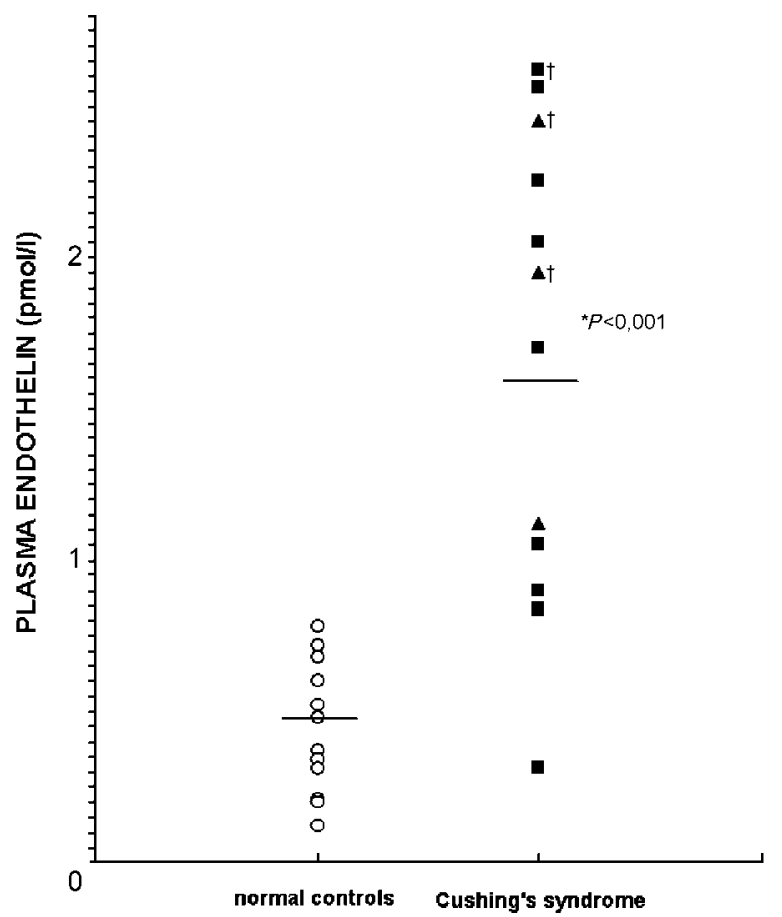

Figure 1 Plasma ET levels in normal controls (O) and patients with Cushing's syndrome: Cushing's disease (ם), adrenal adenoma $(\mathbf{\Lambda})$. $†$, fatal outcome.

than in the healthy controls $(183 \pm 37 / 106 \pm 18$ vs $107 \pm 2.6 / 75 \pm 2.6 \mathrm{mmHg}, \quad P<0.001)$. The serum total cholesterol and triglyceride levels were significantly elevated: $6.94 \pm 1.75 \mathrm{mmol} / \mathrm{l}, \quad P<0.001$ and $3.07 \pm 3.57 \mathrm{mmol} / \mathrm{l}, P<0.05$ respectively. The normal values were $<5.2 \mathrm{mmol} / \mathrm{l}$ for serum cholesterol and $1.7 \mathrm{mmol} / \mathrm{l}$ for serum triglycerides. Significant positive correlation was found between serum total cholesterol and ET- 1 by a linear regression $(r=+0.73$, $P<0.02)$. However, the correlation between ET-1 and arterial blood pressure, plasma cortisol or free urinary cortisol excretion, was statistically insignificant.

Urinary cortisol excretion in the subgroup of seven successfully treated subjects diminished significantly: $1072.9 \pm 298.2$ vs $709 \pm 175.6 \mathrm{nmol} / 24 \mathrm{~h}, P<0.05$. Plasma ET also showed a trend towards reduction: $1.34 \pm 0.69$ vs $0.73 \pm 0.53 \mathrm{pmol} / \mathrm{l}, P>0.05$ (Fig. 2 ). Marked 2- to 4-fold reductions in plasma ET levels was observed in four of the treated patients.

\section{Discussion}

It is well known that the incidence of early atherosclerosis and hypertension in hypercortisolic patients (especially those with Cushing's syndrome) is high, which can explain the high mortality from fatal cardiovascular complications, such as myocardial infarction, aortic rupture and stroke (13). Glucocorticoids potentiate coronary risk factors: hypertension, hypercholesterolemia and hypertriglyceridemia,

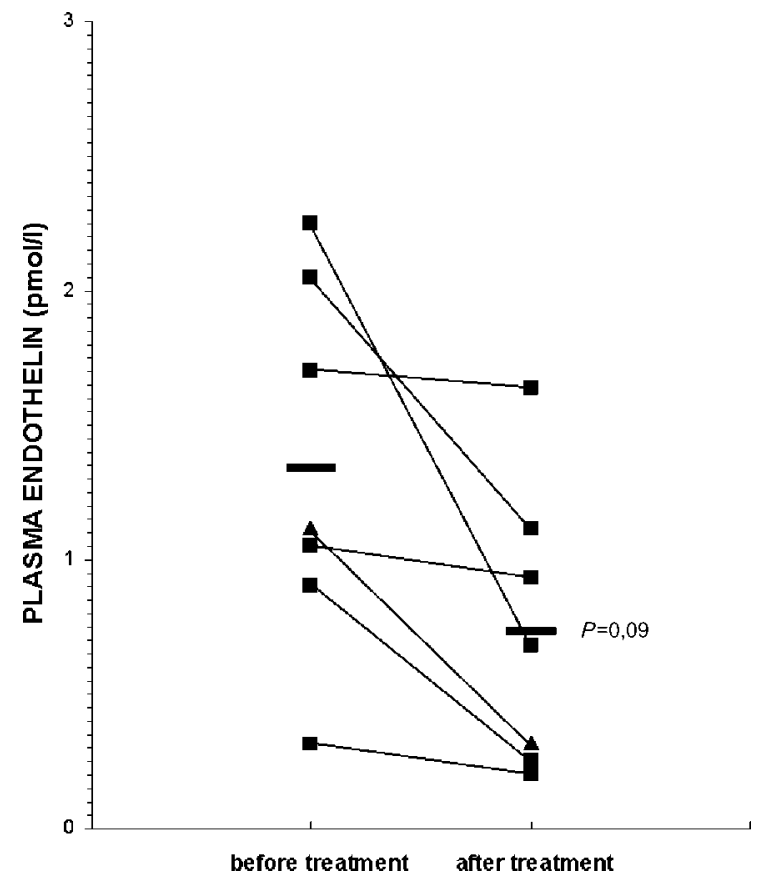

Figure 2 Plasma ET levels before and after successful treatment of Cushing's syndrome patients: Cushing's disease ( $\boldsymbol{\square})$, adrenal adenoma $(\mathbf{\Delta})$. Means as horizontal bars.

impaired glucose tolerance, hyperinsulinemia and insulin resistance (9). Atherosclerotic plaques are found in $30 \%$ of Cushing's syndrome patients. On the other hand, the not-well-enough clarified pathogenesis of cortisol-induced hypertension involves multiple biochemical mechanisms: an activated pressor reninangiotensin system (as a result of elevated renin substrate levels); increased hypertensive response to angiotensin and norepinephrine; reduced activity of the depressor systems including the kalikrein-kinin system, prostaglandins and endothelium-derived relaxing factor $(\mathrm{NO})$.

To the best of our knowledge this is the first study to demonstrate that ET-1 - the most potent vasoconstrictor peptide with marked hypertensive, mitogenic and atherogenic effects - is significantly elevated in patients with untreated active Cushing's syndrome. A trend towards reduction in plasma ET was observed in the patients after successful treatment and normalization of cortisol levels and in several subjects a 2- to 4-fold reduction was found. We cannot state, however, that a definite correlation between hypercortisolism and hyperendothelinemia exists in such a heterogeneous disorder as Cushing's syndrome, which is assumed to be a natural model of premature vascular aging. The persisting high ET levels after the achievement of remission in certain patients are probably due to persistent vascular damage.

Most researchers assume that changes in ET plasma concentrations should be interpreted cautiously since after its synthesis it is released abluminally, i.e. towards 
vascular smooth muscles, where it exerts its action on ET-A and ET-B receptors (14). That means that its circulating level is not a reliable marker of its changes and disturbances at tissue level. As already mentioned above, the catabolic effect of hypercortisolism promotes endothelial damage and increases vascular permeability, which in turn leads to ET-1 hypersecretion in the circulation. It may be suggested that the increased plasma ET-1 levels in this situation reflect the typical Cushing's syndrome endothelial dysfunction and can be considered a biochemical marker for the latter. On the other hand, data exist that elevated circulating ET levels exert pathophysiological effects contributing to development of hypertension, atherosclerosis and coronary artery vasoconstriction. Moreover, the vasoconstrictor effect of ET increases vascular tone in hyperlipidemic patients (15). The significant correlation observed between elevated ET and serum cholesterol in Cushing's syndrome points to a hypothetical role of ET as a humoral atherogenic factor enhancing atherosclerotic processes and endothelial dysfunction in hypercorticism. The rather high ET levels in patients dying subsequently, support the idea of ET as a risk factor and predictor of severe, even lethal cardiovascular complications. It has been proved that in patients with high cholesterol levels ET and lipoprotein (a) are likewise elevated (15). Glucocorticosteroids stimulate the release of ET by vascular smooth muscle cells, and thus exert a permissive effect on the local atherogenic and hypertensive ET action. Moreover, cortisol-induced hypertension is characterized by a reduced activity of the NO depressor system (9). The lack of correlation between ET and arterial hypertension in our study is probably a result of the complex pathogenesis of Cushing's syndromerelated hypertension and the clinical, biochemical and pathomorphological diversity of the syndrome. Recently, it was found that ET-1 infusion in healthy volunteers increases plasma cortisol levels parallel to diastolic arterial blood pressure, which supports the idea of the mediator role of ET-1 on the hypothalamic-pituitary-adrenal axis (3)

The fact that ET exerts direct corticotrope effects on human adrenals and mediates ACTH action $(4,5)$ raises the logical question about the hypothetical pathogenetic role played by ET as adrenocortical stimulator and activator of hyperplastic and growth processes in the adrenal. The ultrastructural localization of ET in benign and malignant adrenal tumors has been ascertained by immunohistochemistry $(16,17)$. Our data indicate that although insignificantly, plasma ET is higher in patients with adrenal adenomas as compared with bilateral adrenal hyperplasia typical of Cushing's disease. Indeed, it would be speculative to assume that the adrenal is the primary source of elevated ET.

ET stimulates directly aldosterone secretion in the zona glomerulosa of the adrenal cortex both in vitro and in vivo, which effect is mediated via ET-A and
ET-B receptors. This raises the suspicion about the role of ET in the pathogenesis of primary hyperaldosteronism (16). In pheochromocytoma, ET stimulates catecholamine release by the adrenal medulla and is secreted excessively together with the catecholamines (11). Available data show that it is hardly likely that the pituitary is the source of elevated ET-1 secretion in the ACTH-dependent Cushing's syndrome caused by corticotropinoma, since it was found that this peptide was expressed by both ACTH-secreting bronchial carcinoid and corticotropinomas $(18,19)$. These authors assume that in the pituitary adenomas ET-1 exerts only local effects by paracrine/autocrine mechanisms.

The neuromodulatory effects of ET in the regulation of hypothalamic-pituitary function (20), the finding of ET receptors in the hypothalamus and pituitary and its CRH-like action are a good reason to suspect the pathogenetic role of ET in Cushing's disease.

Attention should also be focused on the fact that plasma ET is elevated in untreated adrenocortical insufficiency (10). The authors explain that phenomenon with a homeostatic adaptive reaction aimed at correcting the arterial hypotension in this disorder. Presumably along with the sympathetic and renin-angiotensinaldosterone systems, ET activation in adrenocortical insufficiency is an element of neurohumoral response to water and electrolyte disturbances and hypotension. It is less likely that ETs are directly involved in the regulation of the endocrine function of the adrenal cortex (21). Our data demonstrate that both hypo- and hypercortisolism are accompanied by elevated ET levels. This fact should not be interpreted as a paradox, particularly if one assumes that elevated ET plays a compensatory role in Addison's disease, and in Cushing's syndrome it is probably a marker of endothelial dysfunction and atherosclerosis and participates in adrenocortical hyperplasia and tumorigenesis.

In conclusion, plasma ET is significantly elevated in Cushing's syndrome, possibly reflecting activation of the ET system in hypercortisolism. Our study did not permit us to determine whether this elevation is primary or secondary. There are reasons to assume that elevated ET levels mediate the accelerated early atherosclerosis and hypertension typical of this disorder. Moreover, our data demonstrate that patients with significantly elevated plasma ET are at increased risk of potentially fatal cardiovascular events. Future studies with plasma ET level follow-up in subjects with Cushing's syndrome may demonstrate its role as a pathogenetic factor and a prognostic laboratory marker of cardiovascular damage in this disorder.

\section{References}

1 Haak T, Jungmann E, Haak E, Ehrlich S \& Usadel KH. Clinical evidence for a neuromodulator action of endothelin in the hypothalamic-pituitary-adrenal axis in man. Experimental and Clinical Endocrinology and Diabetes 1997105 46-52. 
2 Hinojosa-Laborde C \& Lange D. Endothelin regulation of adrenal function. Clinical and Experimental Pharmacology and Physiology 199926 995-999.

3 Kiefer F, Kellner M, Jahn H \& Wiedemann K. Comparison of the effects of endothelin-1 and -3 on secretion of pituitary hormones in healthy male volunteers. Experimental and Clinical Endocrinology and Diabetes 2000108 378-381.

4 Nussdorfer GG, Rossi GP, Malendovicz LK \& Mazzocchi G. Autocrine-paracrine endothelin system in the physiology and pathology of steroid-secreting tissues. Pharmacological Reviews 199951 403-438.

5 Vierhapper H, Novotny P \& Waldhausl W. Effect of endothelin-1 in man: impact on basal and adrenocorticotropin-stimulated concentrations of aldosterone. Journal of Clinical Endocrinology and Metabolism $1995 \mathbf{8 0} 948-951$.

6 Rossi GP, Belloni AS, Nussdorfer GG \& Pessina AC. Endothelin-1 and the adrenal gland. Journal of Cardiovascular Pharmacology 200035 (Suppl 2) S17-S20.

7 Hinson J, Cameron LA \& Kapas S. Regulation of adrenal vascular tone: role of endothelin-1 and nitric oxide. Endocrine Research 199622 875-879.

8 Mazzocchi G, Malendowicz LK, Musajo FG, Gottardo G, Markowska A \& Nussdorfer GG. Role of endothelins in regulation of vascular tone in the in situ perfused rat adrenals. American Journal of Physiology. Endocrinology and Metabolism $1998 \mathbf{2 7 4}$ E1-E5.

9 Kelly J, Mangos G, Williamson PM \& Whitworth JA. Cortisol and hypertension. Clinical and Experimental Pharmacology and Physiology 199825 (Suppl) S51-S56.

10 Letizia C, Centanni M, Scuro L, Canettieri G, Cerci S, De Ciocchis A et al. High plasma levels of endothelin-1 in untreated Addison's disease. European Journal of Endocrinology 1996135 696-699.

11 Oishi S, Sasaki M \& Sato T. Elevated immunoreactive endothelin levels in patients with pheochromocytoma. American Journal of Hypertension 19947 717-722.

12 Veglio F, Melchio R, Rabbia F \& Chiandussi L. Plasma immunoreactive endothelin-1 in primary hyperaldosteronism. American Journal of Hypertension 19947 559-561.
13 Colao A, Pivonello R, Spiezia S, Faggiano A, Ferone D, Filippella M et al. Persistence of increased cardiovascular risk in patients with Cushing's disease after five years of successful cure. Journal of Clinical Endocrinology and Metabolism $1999842664-2672$.

14 Haynes WG \& Webb DJ. Endothelin as a regulator of cardiovascular function in health and disease. Journal of Hypertension 1998 16 1081-1098.

15 Haak T, Marz W, Jungmann E, Hausser S, Siekmeier R, Gross W et al. Elevated endothelin levels in patients with hyperlipoproteinemia. Clinical Investigator 199472 580-584.

16 Egidy G, Baviera E, Ciuffo G, Corvol P \& Pinet F. Localization of the endothelin system in aldosterone-producing adenomas. Hypertension 200138 1137-1142.

17 Li Q, Grimelius L, Zhang X, Likinius A, Grondal S, Hoog A et al. Ultrastructural localization of endothelin-1 in nonneoplastic, hyperplastic, and neoplastic adrenal gland. Ultrastructural Pathology $199519489-494$.

18 Murakami O, Takahashi K, Sone M, Totsune K, Ohneda M, Itoi K et al. An ACTH- secreting bronchial carcinoid: presence of corticotropin-releasing hormone, neuropeptide $\mathrm{Y}$ and endothelin-1 in the tumor tissue. Acta Endocrinologica 1993128 192-196.

19 Lange M, Pagotto U, Hopfner U, Ehrenreich H, Oeckler R, Sinowatz F et al. Endothelin expression in normal human anterior pituitaries and pituitary adenomas. Journal of Clinical Endocrinology and Metabolism 199479 1864-1870.

20 Lange M, Pagotto U, Renner U, Arzberger T, Oeckler R \& Stalla GK. The role of endothelins in the regulation of pituitary function. Experimental and Clinical Endocrinology and Diabetes 2002110 103-112.

21 Ruschitzka F \& Luescher T. Endothelin: culprit or bystander in Addison's disease? European Journal of Endocrinology 1996135 645-648.

Received 9 April 2003

Accepted 2 September 2003 